\section{International Scientific Journal Theoretical \& Applied Science}

p-ISSN: 2308-4944 (print) e-ISSN: 2409-0085 (online)

Year: 2017 Issue: 11 Volume: 55

Published: $24.11 .2017 \quad$ http://T-Science.org

SECTION 21. Pedagogy. Psychology. Innovations in the field of education.
Dmitry Nikolayevich Chernov

Associate professor, candidate of psychological sciences, Professor of the Department of general psychology and pedagogic, Pirogov Russian National Research Medical University,

Moscow, Russia chernov_dima@mail.ru

Diana Aleksandrovna Lobanova Student of psychological-social faculty, Pirogov Russian National Research Medical University, Moscow, Russia

\title{
THE STUDY OF THE PECULIARITIES OF DEVELOPMENT OF LANGUAGE COMPETENCE IN SENIOR PRESCHOOL CHILDREN WITH GENERAL UNDERDEVELOPMENT OF SPEECH
}

\begin{abstract}
The paper presents the results of empirical research of features of the language competence of children with general underdevelopment of speech and language in senior preschool age using standardized psychometric language test. A comparison of the results of the testing of children with general underdevelopment of speech depending on the types of preschool educational institutions they attend was made. The results are discussed in the context of socio-cultural situations of development, in which children are brought up. We presents the results of the testing of children with general underdevelopment of speech and peers without difficulties in language development. The theoretical and practical significance of the obtained results of empirical research is discussed.

Key words: senior preschool age, general underdevelopment of speech and language, speech, language, language competence.

Language: Russian

Citation: Chernov DN, Lobanova DA (2017) THE STUDY OF THE PECULIARITIES OF DEVELOPMENT OF LANGUAGE COMPETENCE IN SENIOR PRESCHOOL CHILDREN WITH GENERAL UNDERDEVELOPMENT OF SPEECH. ISJ Theoretical \& Applied Science, 11 (55): 206-211.

Soi: http://s-o-i.org/1.1/TAS-11-55-26 Doi: crossef https://dx.doi.org/10.15863/TAS.2017.11.55.26
\end{abstract}

\section{ИССЛЕДОВАНИЕ ОСОБЕННОСТЕЙ СТАНОВЛЕНИЯ ЯЗЫКОВОЙ КОМПЕТЕНЦИИ У СТАРШИХ ДОШКОЛЬНИКОВ С ОБЩИМ НЕДОРАЗВИТИЕМ РЕЧИ}

Аннотация: В работе приведены результаты эмпирического исследования особенностей языковой компетенции детей с общим недоразвитием речи в старшем дошкольном возрасте при помощи стандартизированного языкового психометрического теста. Проведено сопоставление результатов выполнения теста детьми с общим недоразвитием речи в зависимости от типов дошкольных образовательных учреждений, которые они посещают. Результаты обсуждаются в контексте социокультурных ситуаций развития, в которых воспитываются дети. Излагаются результаты выполнения теста детьми с общим недоразвитием речи и их сверстниками без трудностей в языковом развитии. Обсуждается теоретическая и практическая значимость полученных результатов эмпирического исследования.

Ключевые слова: старший дошкольный возраст, общее недоразвитие речи, речь, язык, языковая компетенциия.

\section{Introduction}

В настоящее время все большее кол-во детей испытывают трудности в речеязыковом развитии, что может негативно сказываться на процессе их социализации. Часто таким детям ставят диагноз «общее недоразвитие речи» (далее - ОНР). В данном концепте объединяются различные сложные речевые и языковые расстройства разной степени тяжести (выделяют четыре степени), при которых нарушается формирование фонематико-фонетических аспектов речи, смысловой ее стороны и процесс оперирования средствами грамматики. Часто ОНР выявляется на фоне моторной и сенсорной алалии, детской афазии, дизартрии [3-5; 8-10]. 
При огромном объеме работ, в которых изучение речевого развития детей с ОНР производится при помощи методик, используемых в коррекционно-развивающей деятельности, к сожалению, в нашей стране проведено крайне мало исследований при помощи стандартизированных психометрических тестов, специально разработанных для изучения разных языковых сфер дошкольников.

Целью данной работы стал сравнительный анализ выборки детей с ОНР и нормативной выборки с точки зрения различий в уровне языковой компетенции при помощи психометрического стандартизированного на русскоязычной популяции теста.

Были поставлены следующие задачи:

1. Сравнить детей, посещающих муниципальный детский сад компенсирующего вида и частный детский сад общего типа, по отдельным характеристикам языковой компетенции, и проанализировать полученные результаты с учётом включенности сопоставляемых групп в заданные средовые условия (детский сад компенсирующего вида, частный детский сад общего типа).

2. Сопоставить уровни языкового развития детей с ОНР, с данными, полученными на нормативной выборке детей того же возраста без отклонений в речеязыковом развитии.

\section{Materials and Methods}

Для оценки уровня языковой компетенции детей использовался Гейдельберсгкий тест речевого развития ребенка (авторы - Х. Гримм и Х. Шелер, 1978), который был адаптирован и стандартизирован на выборке из 245 русскоязычных детей в возрасте 4 - 10 лет Н. Б. Михайловой (1990). использовался вариант проведения заданий для детей дошкольного возраста. Тест состоит из 13 заданий-субтестов: «Понимание грамматических структур», «Образование множественного числа существительных», «Имитация грамматических структур», «Коррекция семантически неверных предложений», «Словообразование», «Вариации названий», «Классификация понятий», «Образование степеней сравнения прилагательных», «Взаимосвязь вербальной и невербальной информации», «Кодирование и декодирование наличной интенции», «Конструирование предложений», «Нахождение слов», «Воспроизведение рассказа». Субтесты позволяют оценить уровень языковой компетенции с сферах грамматики, морфологии, семантики слов и предложений, способность комплексно применять языковые знания при работе с целостным текстом. Кроме речелингвистической компетенции группа заданий теста, по замыслу авторов, оценивает уровень речепрагматической компетенции, т.е. способности использовать язык в целях прагматически эффективной коммуникации. После получения данных происходил пересчёт «сырых» баллов в стандартные в соответствии с каждой возрастной группой, из рассматриваемых авторами адаптации теста. В данном случае использовались тестовые нормы для детей 5 л - 5 л 11 мес., 6 л. -6 л. 5 мес., 6 лет 6 мес. -6 л. 11 мес. [7]. Это позволило устранить фактор возрастных различий в уровне языковой компетенции и рассматривать только фактор межиндивидуальных различий в языковых способностях детей.

Для статистической обработки данных использовался компьютерный пакет STATISTICA 12. Применялись следующие статистические методы: одновыборочный критерий $\mathrm{t}$-Стьюдента для сопоставления результатов экспериментальной группы со средними оценками по нормативной выборке, критерий $\mathrm{U}$ - Манна-Уитни для сопоставления выборок детей с ОНР, посещающих разные типы дошкольных образовательных учреждений.

Данные по экспериментальной выборке были собраны в двух детских садах г. Москвы. Первый ДОУ относится к категории муниципальных детских садов компенсирующего типа для детей с нарушением развития речи. В исследовании принимали участие 20 детей подготовительной и старшей группы в возрасте от 5 лет 6 мес. до 6 лет 7 мес, страдающие общим недоразвитием речи. Дети имеют подтвержденный диагноз «фонетикофонематическое недоразвитие, ОНР 4 степени». Второй детский сад является частным садом общего типа, в котором есть группы с детьми, страдающими ОНР. Детям на основании заключения логопеда поставлен диагноз «фонетико-фонематическое недоразвитие, ОНР 4 степени». Обследовано 12 детей с подобным диагнозом в возрасте от 5 лет 6 мес.до 6 лет 8 мec.

Отметим, что ранее нами были обнаружены различия в психолого-педагогических ситуациях развития детей, посещающих данные сады. Если в муниципальном ДОУ компенсирующего типа проводится множество специализированных занятий с таким детьми, то в частном саду воспитатели ориентируются на стандартную программу занятий [6]. Различия в психологопедагогической ситуации развития детей в двух садах можно считать важным социокультурным фактором, на основании которого можно сопоставлять детей из двух садов.

Проводилось сравнение данных, полученных на совокупной выборке детей с ОНР, с результатами исследования языковой компетенции на выборке из 106 старших 
дошкольников, полученных Д.Н. Черновым при помощи Гейдельбергского теста [2]. Возраст контрольной выборки - 5 лет 6 мес. -6 лет 7 мес. Bce дети не посещают школу. Процедура перевода «сырых» баллов в стандартные соответствует руководству по применению русскоязычной версии теста.

\section{Results}

Проведено сопоставление выборок детей с ОНР по уровню выполнения Гейдельбергского теста речевого развития, посещающих муниципальный детский сад компенсирующего типа и специализированные группы частного детского сада. Не обнаружено статистически значимых различий по уровню языковой компетенции ни по одному из субтестов теста. Наибольшие различия, тем неменее, не достигающие $5 \%$ уровня значимости, обнаруживаются по субтесту «Образование сравнительных степеней прилагательных»: в частном саду результаты в среднем чуть выше, чем в ДОУ компенсирующего типа $(\mathrm{p}=0,14)$. Привлекая для интерпретации этих данных сведения об особенностях социокультурных ситуаций развития детей из двух садов, изложенных ранее [6], мы можем констатировать, что хотя условия воспитания детей в муниципальном детском саду компенсирующего типа способствуют лучшей организации коррекционно-развивающей деятельности с детьми, в силу чего, видимо, у детей наблюдается относительная психологическая «сепарация» от родителей, а сами родители занимают несколько отстраненную позицию в вопросах воспитания, это приводит примерно к таким же результатам в уровне языкового развития детей с ОНР, что и в частном саду, работающем на основе общеразвивающей программы, в котором имеются лишь специализированные группы, а психолого-педагогическая квалификация специалистов, судя по проведенной объективной оценке, несколько ниже, чем в муниципальном саду. Видимо, это компенсируется дополнительной заботой о детях в семье, которую, судя по полученным ранее данным, демонстрируют матери детей с ОНР, посещающих частное ДОУ. Это означает, что характер психолого-педагогической ситуации развития ребенка в сочетании с семейной ситуацией развития является интегральным условием речеязыкового развития ребенка с ОНР в старшем дошкольном возрасте. Полученные результаты демонстрируют продуктивность комплексного подхода особенностей психического развития детей в контексте анализа социокультурных ситуаций развития, в которых они воспитываются [1].
Сопоставление совокупной выборки детей с ОНР и данных, полученных по нормативной выборке ранее [2], показали, что наблюдаются статистически значимые различия практически по всем субтестам Гейдельбергского теста, однако направления эти различий не всегда указывают на отставание детей из экспериментальной выборки от сверстников без проблем в речеязыковом развитии. Результаты детей с ОНР ниже, чем в контрольной группе по субтестам «Понимание грамматических структур» ( $<0,001), \quad$ «ловообразование» $(\mathrm{p}<0,001)$, «Образование степеней сравнения прилагательных» (p<0,001), «Классификация понятий» ( $<0,001)$, «Взаимосвязь вербальной и невербальной информации» $(\mathrm{p}<0,001)$. Обратное направление различий обнаружено по субтестам «Имитация грамматических структур» $(\mathrm{p}<0,001)$, «Образование множественного числа существительных» ( $<0,001)$, «Конструирование предложений» (p<0,05), «Вариации названий» $(\mathrm{p}<0,05)$, «Кодирование и декодирование наличной интенции» «Воспроизведение рассказа» $(\mathrm{p}<0,001)$. Не обнаружено значимых различий по субтестам «Коррекция семантически неверных предложений» и «Нахождение слов». Суммация таких разнонаправленных тенденций в итоговых оценках по каждой группе приводит к тому, что не наблюдается статистически значимых различий по среднему уровню языковой компетенции экспериментальной и контрольной групп.

При интерпретации данных необходимо исходить из того, что экспериментальная выборка была собрана из детей, которым поставлен диагноз «фонетико-фонематическое недоразвитие, ОНР 4 степени», т.е. у них наблюдаются остаточные пробелы в развитии фонетико-фонематической и лексикограмматической сторон речи. У таких детей имеются лишь небольшие недостатки в дифференциации отдельных звуков, они испытывают трудности в фонематическом восприятии и удержании в памяти фонематического образа, поэтому часто переставляют звуки и слоги в словах, особенно, когда необходимо повторить слова со сложным слоговым составом. В словах может повторяться какой-то один слог, гласные могут сокращаться в ситуации их стечения. Ребенок может опускать отдельные слоги в словах и добавлять отдельные звуки. Все это приводит к сложностям в коммуникации и спонтанном проговаривании [3$5 ; 8-10]$.

В субтесте «Понимание грамматических структур» необходимо воспринять на слух грамматическую конструкцию и передать ее смысл при помощи небольших игрушечных 
фигурок. Низкий результат может быть следствием того, что дети с четвертой степенью ОНР испытывают сложности в понимании логических отношений, выраженных в грамматической форме. В субтесте «Словообразование» ребенку необходимо образовать различные производные от одного слова. Отставание по этой способности детей с ОНР от сверстников, не имеющих проблем в речеязыковом развитии, является закономерным выражением наблюдающихся систематических ошибок в словообразовании и словоизменении. По нашим данным, выполнение субтеста «Образование степеней сравнения прилагательных» представляет определенные трудности для детей не только старшего дошкольного, но и младшего школьного возраста. Ребенку необходимо, после тренировочного задания, образовать все сравнительные степени прилагательных, которые выражают атрибуты объектов, представленных на картинках. Поэтому отставание от сверстников по данной способности вполне объяснимо сложностью развития ее у детей. В субтесте «Классификация понятий» необходимо выбрать из картинок те объекты, которые могут быть обобщены задаваемой экспериментатором обобщающей категорией. Отмечено, что, хотя дети с ОНР четвертой степени обладают достаточным словарным запасом, они не всегда точно знают и понимают значения слов, особенно, тех, которые редко используются и встречаются в опыте. Работа с данным субтестом также выявила эту проблему у детей. Повидимому, низкий уровень выполнения субтеста «Взаимосвязь вербальной и невербальной информации» может являться следствием вторичных проблем по перцептивной стороне социальной коммуникации, которые испытывают дети с ОНР. В данном субтесте необходимо правильно соотнести эмоционально окрашенное высказывание с картинками, которые мимически выражают то или иное эмоциональное состояние человека.

В то же время можно констатировать, что работа с фонетико-фонематическим недоразвитием речи у детей с ОНР приводит к положительным результатам, что подтверждается более высокими оценками по сравнению с группой нормы по субтесту «Имитация грамматических структур». В этом субтесте ребенку необходимо прослушать высказывания различной грамматической сложности и повторить их. Наблюдаются определенные успехи в сфере морфологии и синтаксиса: дети с ОНР сравнительно хорошо образуют множественное число различных по уровню сложности существительных (субтест «Образование множественного числа существительных») и составляют предложения из представленных им наборов слов (субтест «Конструирование предложений»). Они хорошо ориентируются в наименовании лиц в зависимости от выполняемой ими социальной роли (субтест «Вариации названий») и могут эффективно использовать языковые средства для достижения прагматических целей коммуникации (субтест «Кодирование и декодирование наличной интенции»). Важным результатом коррекционных воздействий на развитие детей является относительно высокий уровень работы с целостным текстом в субтесте «Воспроизведение рассказа»: детям необходимо выслушать рассказ и через некоторое время максимально точно воспроизвести его.

Таким образом, у обследованных детей с четвертой степенью ОНР можно говорить о наличии своеобразного профиля развития разных сфер языковой компетенции, который отличается от нормативных данных, причем далеко не всегда наблюдается снижение развития той или иной способности. Достаточно долговременная психолого-педагогическая работа, которая осуществляется с детьми со стороны ближайшего социального окружения, приводит не только к приближению уровня выраженности некоторых речеязыковых способностей к нормативному уровню, но и даже к некоторому опережению в развитии определенных речеязыковых способностей.

\section{Conclusion}

На основании проведенного эмпирического исследования можно заключить, что создание развивающих и корректирующих ход развития детей с общим недоразвитием речи условий, в независимости от типа посещаемых учреждений при условии деятельного участия семейного окружения в организации социально адекватной жизнедеятельности ребенка, приводит к положительным тенденциям в развитии языковой компетенции. В этом случае не наблюдается тотального отставания в развитии языковых способностей, а по некоторым характеристикам происходит значительная коррекция уровня развития. 


\begin{tabular}{l|lrl|l|ll} 
& ISRA (India) & $=\mathbf{1 . 3 4 4}$ & SIS (USA) & $=\mathbf{0 . 9 1 2}$ & ICV (Poland) & $=\mathbf{6 . 6 3 0}$ \\
Impact Factor: & ISI (Dubai, UAE) $=\mathbf{0 . 8 2 9}$ & PUHU (Russia) $=\mathbf{0 . 2 0 7}$ & PIF (India) & $=\mathbf{1 . 9 4 0}$ \\
& GIF (Australia) & $\mathbf{0 . 5 6 4}$ & ESJI (KZ) & $=\mathbf{3 . 8 6 0}$ & IBI (India) & $\mathbf{4 . 2 6 0}$
\end{tabular}

\section{References:}

1. Chernov D.N. (2011) Psihologoantropologicheskij podhod $\mathrm{k}$ analizu sociokul'turnoj situacii razvitija rebenka // Psihologija obuchenija. - № 10. - P. 4-19.

2. Chernov D.N. (2014) Sociokul'turnaja obuslovlennost' stanovlenija jazykovoj kompetencii. Monografija. - M. TEZAURUS.

3. Diagnostika narushenij rechi $u$ detej i organizacija logopedicheskoj raboty v uslovijah doshkol'nogo obrazovatel'nogo uchrezhdenija (2001). - SPb.: DETSTVO-PRESS.

4. Filicheva T.E., Chirkina G.V. (1993) Podgotovka k shkole detej s obshhim nedorazvitiem rechi $\mathrm{v}$ uslovijah special'nogo detskogo sada. - M.: Izdatel'stvo «Al'fa».

5. Levina R.E., Nikashina N.A. (1968) Harakteristika obshhego nedorazvitija rechi $\mathrm{u}$ detej // Osnovy teorii i praktiki logopedii. - M.: Prosveshhenie.

6. Lobanova D.A., Chernov D.N. (2017) Jempiricheskoe issledovanie osobennostej sociokul'turnoj situacii razvitija starshih doshkol'nikov s obshhim nedorazvitiem rechi // Theoretical \& Applied Science. - 11(55). - P. 201-206.

7. Mihajlova N.B. (1990) Adaptirovannyj variant Gejdel'bergskogo testa rechevogo razvitija detej // Psihologicheskij zhurnal. - T. 11. - №6. - P. 105-112.

8. Sobotovich E.F. (2003) Rechevoe nedorazvitie u detej i puti ego korrekcii: (deti s narusheniem intellekta i motornoj alaliej). - M.: Klassiks stil'.

9. Solov'eva L.G. (1996) Osobennosti kommunikativnoj dejatel'nosti detej s obshhim nedorazvitiem rechi // Defektologija. - № 1. - P. 62-66.

10. Zhukova N.S., Mastjukova E.M., Filicheva T.B. (1998) Logopedija. Preodolenie obshhego nedorazvitija rechi $\mathrm{u}$ doshkol'nikov. Ekaterinburg: ARD LTD. 